\title{
Asymmetric exploitation of two echinoid host species by a parasitic pea crab and its consequences for the parasitic life cycle
}

\author{
C. De Bruyn ${ }^{1,2, *}$, B. David ${ }^{2}$, C. De Ridder ${ }^{1}$, T. Rigaud ${ }^{2}$ \\ ${ }^{1}$ Laboratoire de Biologie Marine (CP 160/15), Université Libre de Bruxelles, 50 avenue F. Roosevelt, 1050 Brussels, Belgium \\ ${ }^{2}$ Biogéosciences, UMR CNRS 5561, Université de Bourgogne, 6 boulevard Gabriel, 21000 Dijon, France
}

\begin{abstract}
Exploitation of more than one host species may increase fitness of parasites, but it also shapes their life cycle and evolution. During its post-metamorphic stages, the pea crab Dissodactylus primitivus parasitizes the echinoids Meoma ventricosa and Plagiobrissus grandis with high prevalence. However, the present study provides evidence that $P$. grandis is infected by adult crabs only, attesting to an unusual asymmetry in host exploitation. Because of its low population densities, $P$. grandis could be a secondarily acquired host, and its addition to the crab life cycle could be adaptive. The latter hypothesis is tested in this study. Choice experiments revealed that adult and juvenile crabs were equally attracted to and able to settle on the 2 hosts. Most adult crab characteristics were not significantly different between the host species, but females living on $P$. grandis had higher fecundity. This asymmetric life cycle, where adult parasites infecting the 2 hosts show different relative fitnesses, looks like a transitory stage as predicted in models which predict the evolution of parasitic complex life cycles. However, this parasite asymmetric exploitation may also be a stable state, which occurs due to insufficient differences in crab fitness between the 2 hosts and the absence of host preference.
\end{abstract}

KEY WORDS: Ecto-parasitism $\cdot$ Multiple hosts $\cdot$ Fecundity $\cdot$ Meoma ventricosa $\cdot$ Plagiobrissus grandis

\section{INTRODUCTION}

Variation in the ability of parasites to exploit different hosts is illustrative of biological adaptation, and many parasites exploit different host species (Poulin 2007). This may have consequences for the evolution of parasite life history traits (Gandon 2004). Patterns are not simple, however, and parasite fitness may be increased by the exploitation of 2 or more host species (Morand et al. 1995, Choisy et al. 2003) but also by the specialisation toward a given host species (Joshi \& Thompson 1995, Pedersen et al. 2005). The exploitation of different host species may also have consequences for the parasite life cycle. Several models suggest that the adaptation of a parasite to several hosts may lead to the selection of a complex cycle in which the parasite will exploit the hosts sequentially (Brown et al. 2001, Choisy et al. 2003, Parker et al. 2003). In all these models, the evolution toward complex cycles begins with the incorporation of a new host in the parasite cycle, either by upward incorporation (i.e. addition of a new host at the end of the parasite cycle, when parasites reach the adult stage and reproduce) or by downward incorporation (i.e. the incorporated host houses larval stages only) (Parker et al. 2003). The addition of a new host in a parasite cycle can be selected if it increases the probability of the parasite finding a mating partner (Brown et al. 2001, Rauch et al. 2005), enhances parasite transmission (Choisy et al. 2003, Parker et al. 2003), or allows higher parasite fecundity (Parker et al. 2003). These models are all constructed for trophically transmitted parasites, where the successive hosts are prey and predators, but Parker et al. (2003) noted that they could be expanded to other transmission modes. While the evolution toward complex parasitic cycles has been investigated at the theo- 
retical level (Brown et al. 2001, Choisy et al. 2003, Parker et al. 2003, Gandon 2004), only few empirical or experimental case studies are available to support the models (Rauch et al. 2005, Loot et al. 2006).

There are ecological similarities between simultaneous and sequential multiple host exploitations. In both cases, there should be an overlap between the spatial distributions of the hosts. In addition, the cost-benefit ratio of exploiting several hosts instead of one should be to the advantage of the parasite. There is, however, one major difference: in the simultaneous design, the whole parasite cycle can be completed on either of the 2 (or more) hosts, while in the sequential design there is an asymmetric exploitation of the 2 hosts: immature parasites infect one host while adults infect the other (Parker et al. 2003, Poulin 2007). All models directly or indirectly suppose transitory stages between simultaneous and sequential cycles. For example, during the process of upward incorporation, the first host should harbour the complete parasite cycle and the second host only adult parasites, while during the downward incorporation the second host should be exploited by immature parasites only (Parker et al. 2003). To our knowledge, this kind of asymmetrical exploitation of 2 hosts, a prerequisite for the evolution of a complex cycle, remains overlooked. Two examples could be the parasitic copepod Lernaeocera lusci, where adults occasionally co-occur with larvae in the intermediate host (Combes 2001), and the marine symbiotic crab Allopetrolisthes spinifrons, where juveniles live both on the final host and a number of other host species (Baeza \& Stotz 2001).

The Pinnotheridae pea crabs have developed a variety of associations with various invertebrates. In this family, the species of the Dissodactylus complex (comprising Dissodactylus and Clypeasterophilus genera) exclusively colonize echinoid hosts on which they live as ectoparasites. In about $70 \%$ of studied cases, at least 2 sympatric host species are exploited, a phenomenon probably favoured by the host-switching behaviour of the crabs (Telford 1978, 1982, Griffith 1987a,b, Pohle 1989, Pohle \& Marques 1995, George \& Boone 2003). $D$. primitivus lives on 2 sympatric burrowing spatangoids, Meoma ventricosa and Plagiobrissus grandis (Telford 1982, Griffith 1987a). Although they have been found exclusively in association with echinoids, recolonization experiments have shown that large juvenile and adult crabs crabs are able to move toward another sea urchin (De Bruyn et al. 2009). Unlike $M$. ventricosa, $P$. grandis is considered relatively rare, and, as such, its behaviour has been poorly studied (Kier \& Grant 1965). Both species stay burrowed under 1 to $2 \mathrm{~cm}$ of sediment during the daytime and become epibenthic at night. $M$. ventricosa is a slow-moving echinoid, while $P$. grandis is much more active but dur- ing shorter periods (M. Telford, C. De Bruyn et al. pers. obs.). D. primitivus is a parasite of its host species: it imposes a fitness cost by feeding on the host tegument and spines (demonstrated for $M$. ventricosa), inducing wounds (Telford 1982, De Bruyn et al. 2009). After a short series of free larval stages, the whole post-metamorphic crab cycle is fulfilled on $M$. ventricosa (De Bruyn et al. 2009). Contrary to observations on M. ventricosa, reports of $D$. primitivus on P. grandis only mentioned adult crabs (Telford 1982). This led to the idea that $M$. ventricosa is the common host for $D$. primitivus, and $P$. grandis an alternative host. Therefore, this crab is a good example of a parasite exploiting 2 host species asymmetrically.

The aim of the present study was to investigate the hypothesis of an asymmetric parasitism by addressing 3 main questions rooted in the ecological differences separating the 2 hosts: (1) Are the 2 hosts equally suitable habitats for immature crabs? This question was explored by comparing the population density of the 2 hosts, the proportion of juvenile vs. adult crabs living on the 2 hosts, and using a choice experiment. (2) Are the 2 hosts equally successful locations for the adult crabs to meet a mating partner? This was investigated by comparing the sex ratios and the probability of finding couples on the 2 hosts. (3) Are fitness traits of female crabs similar on the 2 hosts? This question was addressed by comparing the female crab sizes and reproductive parameters between the 2 hosts.

\section{MATERIALS AND METHODS}

Sampling site and general sampling method. Meoma ventricosa, Plagiobrissus grandis and their parasite Dissodactylus primitivus were collected by SCUBA diving in March 2007 in the western part of Discovery Bay lagoon, on the north coast of Jamaica (De Bruyn et al. 2009). The echinoids were collected at depths of 1.5 to $3 \mathrm{~m}$, in patches of coral sand surrounded by areas of the sea grass Thalassia testudinum. The 2 host species are found by digging at the end of the trails created by their movement (Kier \& Grant 1965). Moreover, specimens of a non-host sympatric sea urchin Clypeaster rosaceus were also collected to determine whether they harbored $D$. primitivus and to use them in choice experiments (see 'Host choice').

The estimation of density of the 2 host species was made simultaneously by searching the sea urchins under the sediment in 12 transects of $10 \mathrm{~m}$ long $\times 2 \mathrm{~m}$ wide $\left(20 \mathrm{~m}^{2}\right)$, randomly distributed in the study area. These investigations were made prior to crab collections.

The crab census was made as described in De Bruyn et al. (2009). The echinoids were collected and immediately slipped into separate bags or baskets to avoid 
any crab loss or transfer between hosts. Transfer to the laboratory was made within 30 min of capture. Each echinoid was measured to the nearest $\mathrm{mm}$ with a calliper rule. All crabs were removed with thin entomological forceps, counted, measured under a stereomicroscope (maximum cephalothorax width, nearest $0.5 \mathrm{~mm}$ ) and sorted according to gender. The gender and the maturity stage (juveniles vs. adults) were differentiated as described in De Bruyn et al. (2009). Several criteria were compared between host species: parasite prevalence (proportion of echinoid infected), parasite mean burden (mean number of crabs per host), proportion of ovigerous female crabs, proportion of recently fertilized females (proportion of females with embryos at early developmental stage, i.e. before segmentation), and finally the fecundity of females corrected for their size. To test whether 1 of the 2 hosts might be a better mating site than the other, we classified the groups of adult crabs from each echinoid individual into 2 categories (De Bruyn et al. 2009): 'mating possible' (when both sexes were present with at least a heterosexual couple per host) or 'no mating possible' (only one sex was present, e.g. single crabs, couples or groups of adults of the same gender).

For continuous data, normality and homogeneity of the variances were tested prior to analyses. Non-parametric tests were used when these conditions were not met (Wilcoxon rank scores and Kruskal-Wallis tests for comparisons of 2 or more independent groups, respectively, and Spearman's rank correlation for testing links between 2 variables). In other cases, general linear models (ANOVA or ANCOVA) or $t$-tests were used (e.g. comparisons of crab fecundities or sizes). Categorical data were analyzed with Fisher's exact tests or with logistic regressions. Models including several factors or covariables and their interactions were reduced by backward elimination of non-significant terms. The models presented are those that minimize Akaike's information criterion (AIC) (Quinn \& Keough 2002).

Host choice. To test crab preference between host species, a binary choice design was used. Observations were made in $60 \times 30 \times 30 \mathrm{~cm}$ aquaria filled with oxygenated seawater. Each aquarium was divided into 2 equal compartments by a perforated translucent partition allowing water circulation. The partition left a narrow free space $(2 \mathrm{~cm})$ above the floor of the aquarium, allowing crab, but not echinoid, passage. The aquaria were filled, and the echinoids were set in place (1 sea urchin in each compartment) with running seawater and oxygen supply $15 \mathrm{~min}$ before starting each run. The air pump and the flow of water were stopped $5 \mathrm{~min}$ before each run to avoid hydrodynamic disturbances. For each run, 6 crabs (without sex distinction) were centrally placed under the partition. The position of the crabs (i.e. on echinoid 1, on echinoid 2 or free in the aquarium) was observed $1 \mathrm{~h}$ later. Seven to 30 runs were made for each experiment, with new crabs and echinoids being used for each run. The position of the different echinoid species was permuted every run. Crabs used in these experiments were collected on Meoma ventricosa or Plagiobrissus grandis, but used separately. The gender of the crabs being tested was not considered since we found no difference in sex repartition between the 2 hosts (see 'Results'). Echinoids of similar sizes were used for all runs.

Six experiments were conducted. The first examined the behaviour of crabs when 2 Meoma ventricosa were offered, to check whether the crabs tend to show a preference for 1 of the compartments. The next 3 experiments tested preference for $M$. ventricosa vs. Plagiobrissus grandis. Adult and juvenile crabs from $M$. ventricosa were tested separately to estimate potential differences of host choice based on maturity stage. Juveniles used in the experiments were of the same size classes as those found during the census. Only 7 runs were made with adult crabs from $P$. grandis due to the scarcity of this sea urchin in the lagoon. This rarity also prevented us from testing further preference combinations for crabs infecting $P$. grandis. The fifth experiment tested host attractiveness by offering a non-host echinoid Clypeaster rosaceus to adult crabs collected on $M$. ventricosa. C. rosaceus, sympatric with $M$. ventricosa and P. grandis, was never found to harbor Dissodactylus primitivus (Griffith 1987a). This was confirmed by our sampling, as no $D$. primitivus were found on the 57 C. rosaceus collected. Finally, design neutrality was checked by offering 2 C. rosaceus to the crabs.

Crab choice was quantified for each run by calculating the proportion of crabs found on echinoid 1 and on echinoid 2, excluding crabs that remained free in the aquarium (i.e. those that made no choice at all). The proportion of these latter crabs was also recorded for analyses. Since data did not satisfy homoscedasticity and normality conditions, non-parametric tests were used to compare these proportions according to experimental series. Within groups, Wilcoxon signed rank tests were used to test if the distribution of the crabs between the 2 hosts departed from random distribution (i.e. $50 \%$ on each host). Wilcoxon rank score tests were used for comparisons between groups. All statistical tests were made using the program SAS JMP 5.0.1.2 (SAS Institute).

\section{RESULTS}

\section{Relative abundance of hosts}

The average density of Meoma ventricosa species was 2.0 ind $10 \mathrm{~m}^{-2}$ (minimum $=0$, maximum $=10$ in the 
12 transects) and that of Plagiobrissus grandis species was 0.2 ind. $10 \mathrm{~m}^{-2}$ (minimum $=0$, maximum $=2$ ). These 2 density estimates were significantly different (Wilcoxon rank score test: $Z=-2.5 ; \mathrm{p}=0.01$ ).

\section{Prevalence and distribution of Dissodactylus primitivus on their hosts}

A total of 116 and 47 crabs were collected on 49 Meoma ventricosa and on 38 Plagiobrissus grandis, respectively (to increase sample size, we actively searched for P. grandis hosts; therefore the relative proportion of hosts did not reflect their actual abundance, see 'Materials and methods: Sampling site and general sampling method'). When juvenile crabs were included in the analysis, both prevalence and mean burden were significantly higher on $M$. ventricosa than on $P$. grandis, but these parameters became similar when only adult crabs were considered (Table 1). Very few juveniles were found on $P$. grandis (4 crabs), and correspondingly, the proportion of juveniles was much lower on $P$. grandis than on $M$. ventricosa (Fig. 1; Wilcoxon rank score test: $Z=-4.61, \mathrm{p}<0.0001)$. In addition, these juveniles were larger than those found on $M$. ventricosa (Fig. $2 ; F_{1,70}=9.1, \mathrm{p}<0.004$ ). Average cephalothorax width was more than $4 \mathrm{~mm}$, close to the limit between juveniles and adults (De Bruyn et al. 2009), while all sizes of juveniles were found on $M$. ventricosa (between 1.4 and $4.9 \mathrm{~mm}$ ). The size of adult parasites was the same between the 2 hosts (Fig. $2 ; F_{1,54}=0.36, \mathrm{p}=$ 0.55 for males; $F_{1,52}=1.63, \mathrm{p}=0.21$ for females). The 2 hosts were much larger than their parasites (average width \pm SE: $121 \pm 13$ and $114 \pm 18 \mathrm{~mm}$ for $M$. ventricosa

Table 1. Dissodactylus primitivus infecting Meoma ventricosa and Plagiobrissus grandis. Prevalence and mean burden of $D$. primitivus parasitizing its 2 hosts $M$. ventricosa and $P$. grandis. Comparisons are made counting all crabs (juveniles plus adults) and the adult crabs only. n: number of crabs; $\mathrm{N}$ : number of echinoids

\begin{tabular}{|lccc|}
\hline & M. ventricosa & P. grandis & $\mathrm{p}$ \\
\hline All crabs & & & \\
$\mathrm{n}$ & 116 & 47 & \\
Prevalence & 0.90 & 0.68 & $0.02^{\mathrm{a}}$ \\
Mean burden & $2.4(1.9-2.8)^{\mathrm{b}}$ & $1.2(0.9-1.6)^{\mathrm{b}}$ & $0.0006^{\mathrm{c}}$ \\
& & & \\
Adult crabs & & 43 & \\
$\mathrm{n}$ & 66 & 0.68 & $0.50^{\mathrm{a}}$ \\
Prevalence & 0.76 & $1.2(0.9-1.6)^{\mathrm{b}}$ & $0.60^{\mathrm{c}}$ \\
Mean burden & $1.3(1.0-1.7)^{\mathrm{b}}$ & & \\
N & 49 & 38 & \\
aFisher's exact test & & \\
b95\% confidence interval & & \\
cWilcoxon ranks score test & & \\
\hline
\end{tabular}

and $P$. grandis, respectively). In $M$. ventricosa, there was a positive correlation between mean crab burden, juveniles included, and host size (Spearman's rank correlation: $\rho=0.41, p=0.003$ ), but not between prevalence and host size (logistic regression: Maximum Likelihood Chi-Squared analysis, $\chi_{1,112}^{2}=1.42, p=0.23$ ). In $P$. grandis neither the mean burden nor the prevalence were related to host size $\left(\rho=0.28, p=0.23\right.$ and $\chi_{1,38}^{2}=$ $2.78, \mathrm{p}=0.10$, respectively).

Crab sex ratios were not different between the 2 host species (Fisher's exact test: $\mathrm{p}=0.69$ ), and close to $1: 1$

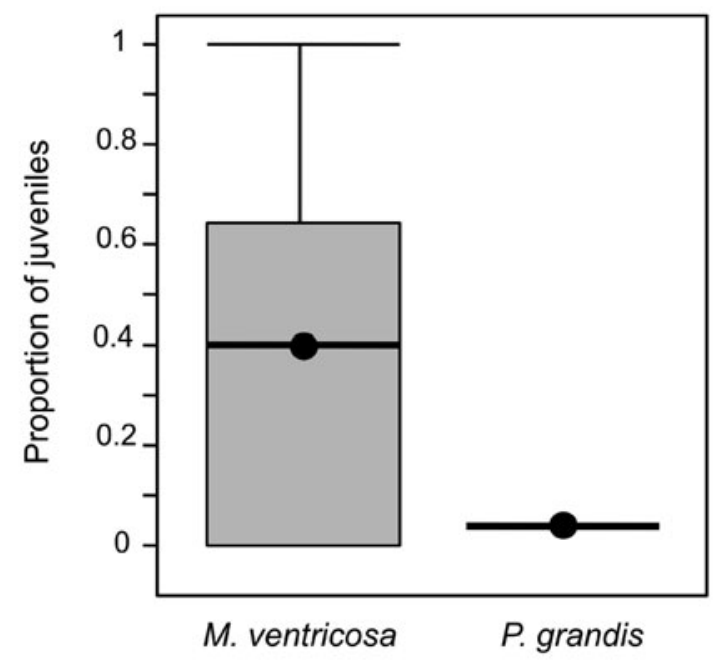

Fig. 1. Dissodactylus primitivus infecting Meoma ventricosa and Plagiobrissus grandis. Proportion of juvenile crabs per individual host based on host species. Boxes and whiskers show interquartile and interdecile ranges, respectively; bold horizontal lines show the median and means $(\bullet)$

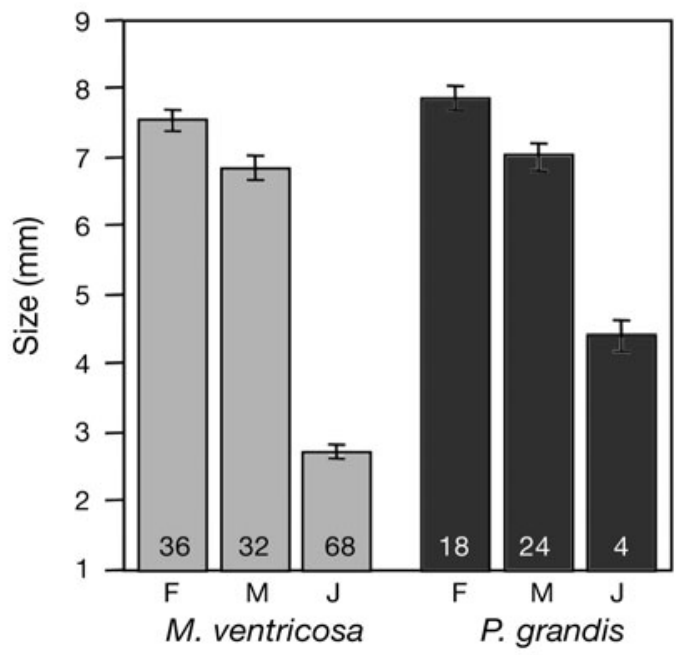

Fig. 2. Dissodactylus primitivus infecting Meoma ventricosa and Plagiobrissus grandis. Average size of crabs (mean \pm SEM) based on gender and host species infected. The number of crabs is given at the bottom of each bar. F: females; M: males; J: unsexed juveniles 
(59.1\% males on Meoma ventricosa, $\mathrm{n}=66$, and $53.5 \%$ males on Plagiobrissus grandis, $\mathrm{n}=43$ ). The proportion of hosts haboring parasites for which mating was potentially possible did not differ between $M$. ventricosa and $P$. grandis (Table 2a; Fisher's exact test: $\mathrm{N}=$ $61, \mathrm{p}=0.43$ ). The result remains the same using a more conservative approach in which ovigerous female parasites which had already mated were considered not available for immediate mating (Table 2b, Fisher's exact test: $\mathrm{N}=61, \mathrm{p}=0.11$ ).

The proportion of adult females that were ovigerous did not differ significantly between host species (Fisher's exact test: $\mathrm{N}=54, \mathrm{p}=0.37$ ). Neither the sizes of ovigerous females (female width $=7.61 \pm 0.16 \mathrm{~mm}$ SEM on Meoma ventricosa and $7.86 \pm 0.18 \mathrm{~mm}$ SEM on Plagiobrissus grandis) nor the proportion of females carrying developed vs. young embryos differed significantly between host species $\left(t_{35}=1.02, \mathrm{p}=0.32\right.$; Fisher's exact test: $\mathrm{N}=37, \mathrm{p}=0.20$, respectively). How-

Table 2. Dissodactylus primitivus infecting Meoma ventricosa and Plagiobrissus grandis. Number of echinoids harboring the 2 categories of adult crab groups based on mating possibility. (a) Mating possible: group of crabs consisted of at least 1 male and 1 female; no mating possible: single crabs, couples or groups of the same gender. (b) Mating possible: same as (a), but couples with ovigerous females were excluded; no mating possible: same as (a), but couples with ovigerous females were added (see 'Prevalence and distribution of Dissodactylus primitivus on their hosts')

\begin{tabular}{|c|c|c|c|}
\hline & Host & Mating possible & No mating possible \\
\hline \multirow[t]{2}{*}{ (a) } & M. ventricosa & 17 & 20 \\
\hline & P. grandis & 14 & 10 \\
\hline \multirow[t]{2}{*}{ (b) } & M. ventricosa & 13 & 24 \\
\hline & P. grandis & 14 & 10 \\
\hline
\end{tabular}

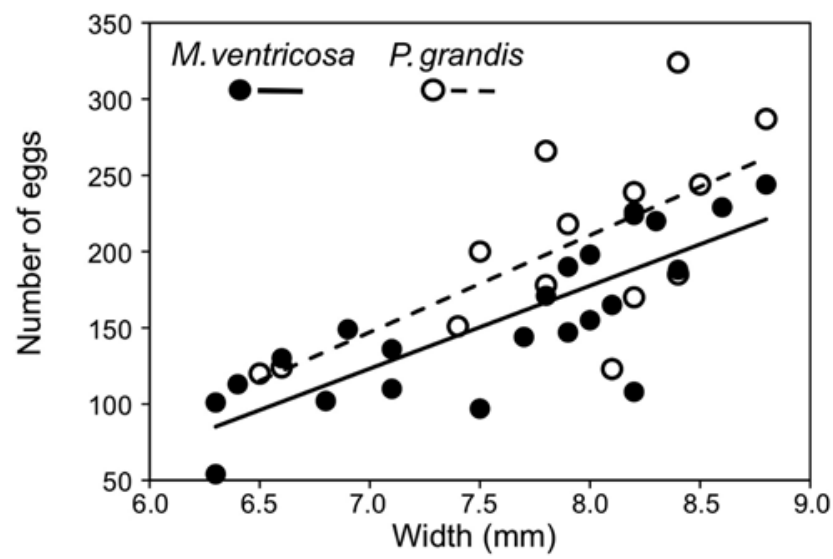

Fig. 3. Dissodactylus primitivus infecting Meoma ventricosa and Plagiobrissus grandis. Number of eggs carried by ovigerous female crabs based on crab size and host species ever, the average number of eggs carried by ovigerous female crabs found on $P$. grandis was larger than on M. ventricosa (Fig. 3, ANCOVA global model: $F_{3,33}=$ $17.9, \mathrm{p}<0.001$; effect of female size: $F_{3,33}=37.9, \mathrm{p}<$ 0.001 ; effect of host species: $F_{3,33}=5.2, \mathrm{p}<0.03$; model reduced from an original model including female size as covariate, host species and egg maturation stage as fixed factors, and all interactions).

\section{Choice experiments}

When 2 Meoma ventricosa were offered, the crabs distributed themselves equally between the 2 sides of the aquaria (Fig. 4a). Neither adult nor juvenile crabs

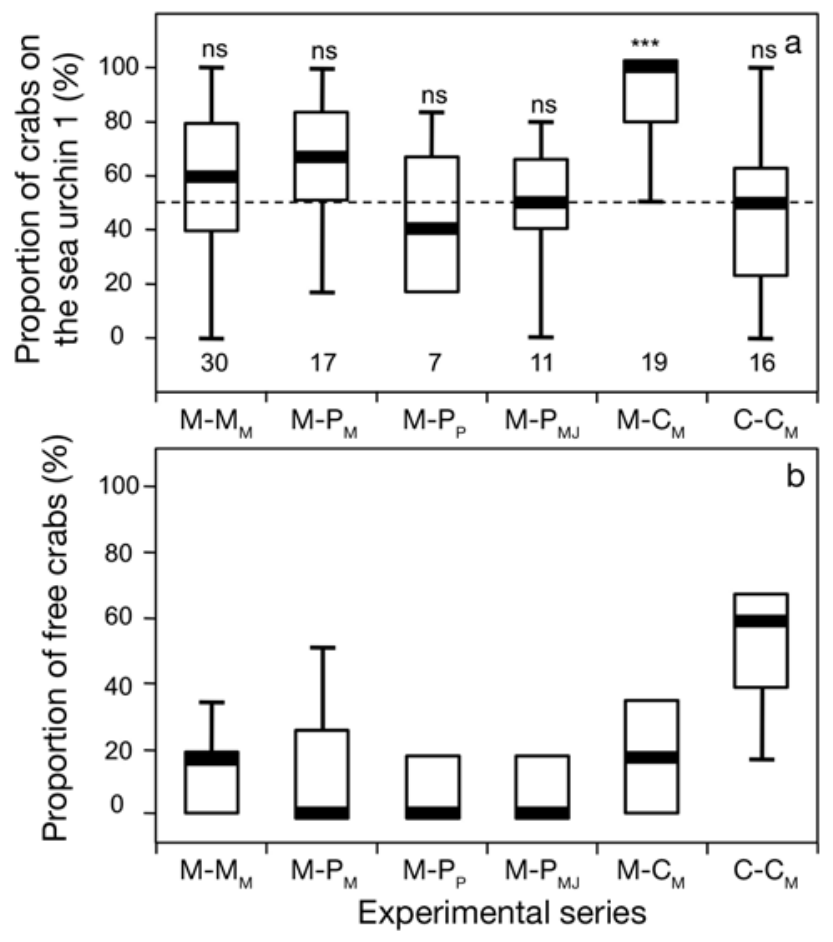

Fig. 4. Average distribution of crabs $1 \mathrm{~h}$ after the beginning of the choice experiments, based on the experimental series. (a) Differential choice: proportion of crabs found on echinoid species 1, among crabs settled on echinoids (see below for echinoid species order in the test). (b) Proportion of crabs (out of a total of 6) not settled on echinoids (i.e. remaining on the aquarium floor) Experimental series are as follows: the first letter is for species 1, the second for species 2 and subscript letters are for the host species from which the crabs being tested were collected. M: Meoma ventricosa; P: Plagiobrissus grandis; C: Clypeaster rosaceus. All subscripts refer to host species from which the adult crabs were collected, with the exception of $\mathrm{M}-\mathrm{P}_{\mathrm{MJ}}$ where subscript J refers to juvenile crabs. Shaded bars are the medians, boxes and whiskers depict the interquartile and interdecile ranges, respectively. Significance levels after Wilcoxon signed rank tests for the deviation from balanced distribution (dotted line) are given above the bars: ns: $p>0.05$; ${ }^{* * *} p<0.0001$. Number of runs per experiment are given in (a) 
collected on $M$. ventricosa showed a significant preference for one or the other echinoid host, $M$. ventricosa and Plagiobrissus grandis; there was nevertheless a slight trend for adult crabs to be more attracted by their host of origin ( $\mathrm{p}=0.054$, Fig. 4a). No significant trend was observed for the crabs taken on P. grandis. In contrast, their original host was markedly attractive for crabs when the choice was offered between $M$. ventricosa and the non-host echinoid Clypeaster rosaceus (Fig. 4a). There was no bias in the experimental design, since Dissodactylus primitivus showed no preference for one side or the other of the aquarium when 2 C. rosaceus were provided. When at least one natural host was provided, almost no crab was found free in the aquarium after $1 \mathrm{~h}$ (they were found between the spines of one or the other echinoid) (Fig. 4b). When only a non-host echinoid species of $D$. primitivus was provided in both compartments (C- $\mathrm{C}_{\mathrm{M}}$ group, Fig. 4), most crabs did not make any choice and remained free in the aquarium (Fig. 4b) (Wilcoxon rank score tests comparing $\mathrm{C}-\mathrm{C}_{\mathrm{M}}$ group with others: all $\mathrm{p}<0.0002$ ), showing that the crabs excluded this non-host sea urchin as potential shelters.

\section{DISCUSSION}

The 2 sympatric spatangoids Meoma ventricosa and Plagiobrissus grandis are both hosts of the crab Dissodactylus primitivus. Mean burden and prevalence were lower on $P$. grandis than on $M$. ventricosa. The 2 hosts nevertheless harbored the same number of adult parasites, but juveniles were much more abundant on M. ventricosa. The rare juveniles found on $P$. grandis were all close to sexual maturity, and we can consider that only the adult stages infect $P$. grandis, while all post-metamorphic stages occur on $M$. ventricosa (see De Bruyn et al. 2009). Therefore, P. grandis should be considered as a specific type of host harbouring only adult parasites. Owing to this characteristic, and to the scarcity of $P$. grandis, this echinoid may be considered as a facultative host for $D$. primitivus; however, parasites reproduce on the species as well as, or even better (see below) than, on $M$. ventricosa.

Although most $(70 \%)$ species of the Dissodactylus complex exploit 2 or more host species, Dissodactylus primitivus is the first reported to display an asymmetric exploitation of its hosts (Telford 1978, 1982, Griffith 1987a,b, Pohle 1989, Pohle \& Marques 1995). However, since the life cycles of this complex of crabs remain largely unstudied, further research is needed to assess whether or not the case of $D$. primitivus is unique. D. primitivus, like many symbiotic marine crabs (Baeza \& Thiel 2007), displays frequent hostswitching behavior. A previous field experiment showed that both juvenile and adult crabs rapidly colonize uninfected Meoma ventricosa host within a few days (De Bruyn et al. 2009). A first hypothesis explaining asymmetry in host exploitation was that juveniles are not attracted by Plagiobrissus grandis during host switching and therefore do not settle on this host. Our experimental choice test did not support this hypothesis. The 2 host species were equally attractive to both adult and juvenile crabs. This contrasts sharply with the choice between host and non-host echinoids: $D$. primitivus is able to detect its usual hosts $M$. ventricosa and is not attracted by other potential refuges. Therefore, their 2 hosts equally attract $D$. primitivus crabs of all stages, either visually or chemically. This differs from other Dissodactylus species that generally display different attractiveness according to the host species (Gray et al. 1968, Reeves \& Brooks 2001). Our choice experiment nevertheless suggests that there could be a slight imprinting for adult crabs living on $M$. ventricosa, since they showed a slight trend towards the host species where they were captured (Fig. 4). This suggests that crabs spend more time on M. ventricosa than on P. grandis.

An alternative hypothesis explaining the discrepancy between field and experimental data could be that the free pre-metamorphic larvae are unable to settle on Plagiobrissus grandis. This hypothesis can, in turn, be related to 4 non-exclusive explanations that remain to be explored: (1) Since our choice experiments only tested short-term preference, P. grandis might not be a suitable host for long-term settlement and survival of earliest juveniles. (2) As P. grandis is the host where female crabs show better fitness (see below), adults may actively remove young juveniles from this host to avoid overexploitation of this resource. This would be different from Allopetrolisthes spinifrons where adults tolerate small recruits on their hosts (see Baeza et al. 2002). (3) A difference in host behaviour could explain a differential accessibility. Both echinoids spend the daytime burrowed in the sediment, but Meoma ventricosa moves slowly over the sediment surface throughout the night, whereas $P$. grandis makes short fast runs and spends little time unburrowed (with previous authors even suggesting it remains burrowed always; Chesher 1969, Hammond 1982). The burrowing behavior of $P$. grandis could prevent larval recruitment and consequently limit the occurrence of juvenile crabs. This last explanation supposes that the small juveniles do not move between hosts once installed on $M$. ventricosa. This is supported by the observations of De Bruyn et al. (2009), who showed that only large juveniles and adults were able to colonize new hosts. (4) Another possibility is that recruits use chemical cues, and that $P$. grandis does not release chemical cues that would allow small recruits to find this host. Chemodetection is not 
an exception within the Dissodactylus complex (Johnson 1952, Gray et al 1968), but its use during recruitment has never been demonstrated. Asymmetrical exploitation of hosts has already been shown in another marine symbiotic crab, the porcellanid Allopetrolisthes spinifrons. In this case, adults live only on a sea anemone, but the larvae and the small juveniles are also found on several intermediate hosts (Baeza \& Stotz 2001). In contrast to Dissodactylus primitivus, additional hosts have been observed for the juvenile stages of $A$. spinifrons are for the juvenile stages. Here, the juveniles are attracted to, and try to settle on the sea anemone, but adults can remove them (if they are too large) to preserve this scarce resource, leading juveniles to colonize other hosts.

Why does a facultative host occur in the Dissodactylus primitivus cycle? Generally, the introduction of an additional host into the life cycle provides adaptive advantage to the parasite (Poulin 2007). A first hypothesis is that the additional host could increase the probability for the adult parasites to find a mating partner (Brown et al. 2001). However, we found no significant difference between the 2 hosts for several reproductive parameters (proportion of heterosexual couples, proportion of ovigerous females, reproduction synchrony). A supplementary argument against an 'ideal mating site' hypothesis comes from the fact that pinnotherid females possess 2 spermathecae, allowing sperm storage (Guinot 1979, Bell \& Stancyk 1983). This trait has not been studied in $D$. primitivus, but comparison with closely related species suggests that $D$. primitivus also has this characteristic. Owing to the hostswitching behavior, fertilization and incubation locations can therefore be different. A second hypothesis explaining the addition of a supplementary host is the increase of the parasite reproductive success (Parker et al. 2003). This is supported by our data, since the ovigerous female crabs found on Plagiobrissus grandis produce more eggs than those living on Meoma ventricosa, while no significant difference in size was found between the 2 hosts. $P$. grandis could be a host providing better resources. However, according to Telford (1982), feeding behavior and gut contents of adult crabs are similar on both hosts. This difference in fecundity could be linked to other factors. Owing to its burrowing behavior, $P$. grandis may provide a habitat less exposed to predators, and therefore a less stressful one, allowing better resource allocation to reproduction. Alternatively, the 'best quality' females could win the competition, and the observed pattern of fittest females on $P$. grandis could result from a competition process.

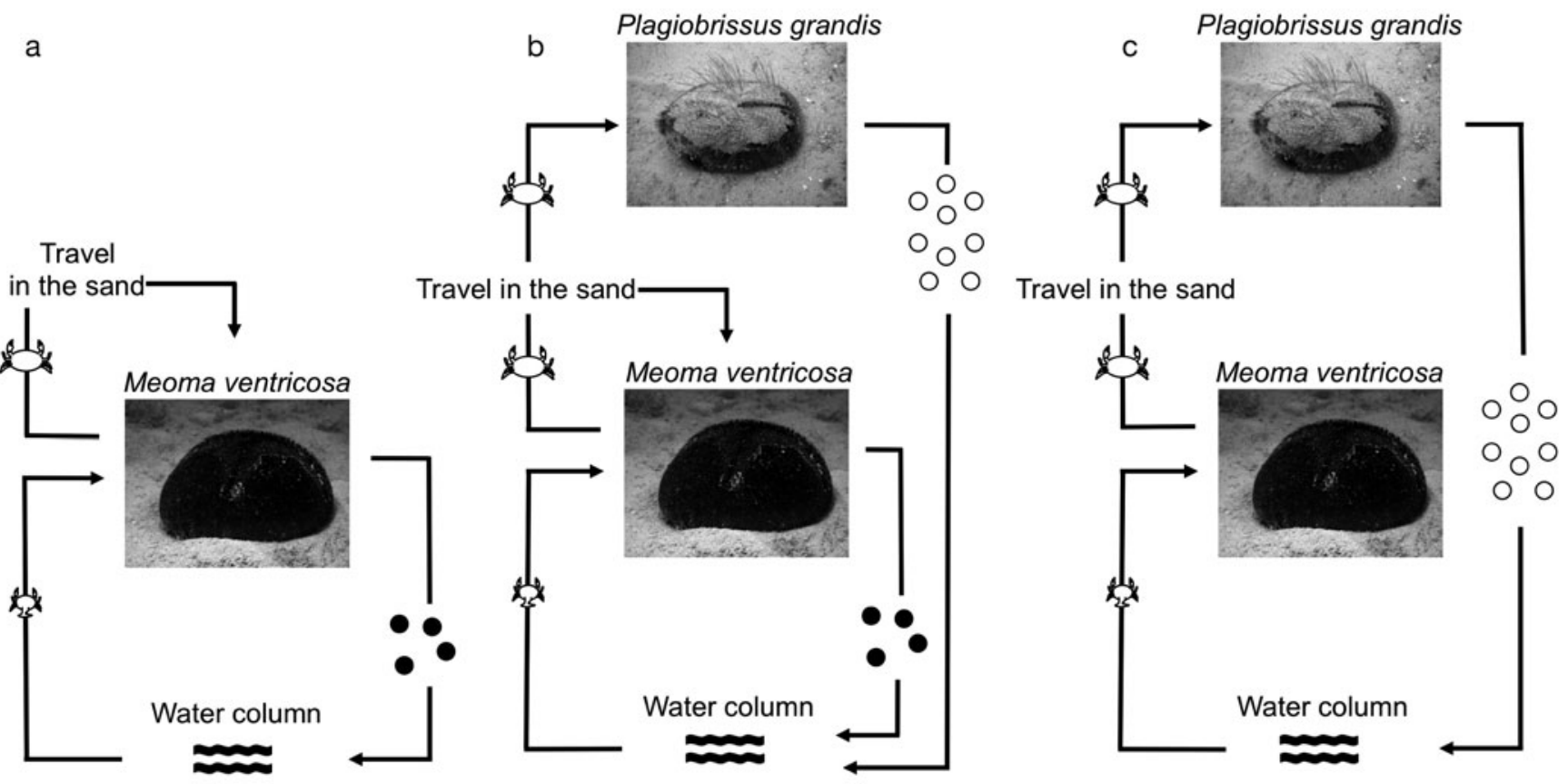

Fig. 5. Dissodactylus primitivus. Suggested evolution of the life cycle of D. primitivus. (a) Hypothetical ancestral 1-host cycle: recruitment, reproduction and brooding occur on Meoma ventricosa. (b) Present life cycle with 2 hosts: recruitment and juvenile growth occur only on $M$. ventricosa, while reproduction and brooding take place on both $M$. ventricosa and Plagiobrissus grandis. (c) Hypothetical future evolution with 2 successive hosts: recruitment and juvenile growth take place on $M$. ventricosa, but reproduction occurs only on $P$. grandis. Circles are planktonic larvae (- larvae from $M$. ventricosa crabs; O: larvae from $P$. grandis crabs); crabs depicted as small represent first juvenile stage (infective stage), larger crabs represent adults 
The asymmetrical host usage during the life cycle of Dissodactylus primitivus displays some similarities with the transitional stage predicted by the 'upward incorporation' model of evolution of complex parasite life cycles (Parker et al. 2003). This model proposes that a single host life cycle can evolve toward a 2-host life cycle if adult parasites are able to infect a new host after the original host, the latter becoming subsequently an intermediate host. This evolution would be possible if, during a transitional stage, adult parasites increased their lifetime reproductive success on the second host relative to the first one. Finally, achievement of the 2-host life cycle would be possible after the selection of a delayed maturity on the first host. $D$. primitivus presents a life cycle in which only the first host is used for larval recruitment and growth, while the 2 hosts harbor the reproduction of the adult crabs, and in which females have a higher fecundity on the facultative host (Fig. 5b). This situation could have evolved from a single-host life cycle (Fig. 5a), because Meoma ventricosa is the more accessible host, where the whole crab life cycle can be achieved. Because fecundity of females living on Plagiobrissus grandis is higher relative to those living on $M$. ventricosa, the present situation could evolve toward a 2-host life cycle, where $M$. ventricosa would be the intermediate host and $P$. grandis the final host (Fig. 5c) (Parker et al. 2003). However, the present situation may also be quite stable for at least 3 reasons. First, the relative fitness benefits have to be quite high to allow selection of reproductive suppression on the first host (Parker et al. 2003), and the observed fecundity benefits for female crabs living on P. grandis are not that important (around 17\% more eggs). Second, the scarcity of $P$. grandis, and thus the limited opportunities females have to infect it, could counterbalance its intrinsic quality as resource. The higher fecundity would therefore concern too few females to lead to a fixation of reproduction on P. grandis (Loot et al. 2006). Third, the absence of crab preference for one or the other host suggests an absence of specialization for reproduction on P. grandis, and therefore no ongoing selection toward a 2-host life cycle. In conclusion, we suggest that the observed present situation could be illustrative of an equilibrium resulting from antagonistic driving forces: better resources on the one hand, promoting a sequential life cycle on 2 hosts, and scarcity of the best host on the other hand, preventing the system from evolving further. However, more information (e.g. on temporal variation in host biology, or about the causes of crab mobility) would be necessary to improve our understanding of this life cycle and its evolution.

Acknowledgements. We are grateful to the staff of the Discovery Bay Marine Laboratory for providing accommodation and laboratory facilities. The work was supported by a doctoral grant from the Belgian National Science Association (FRIA) (to C.D.B.) and by research grants from the Fonds de la Recherche Scientifique (FNRS) (to C.D.B. and C.D.R.) and Région Bourgogne (to B.D. and T.R.). It is a contribution of the Centre Interuniversitaire de Biologie Marine (CIBIM) and of the groups 'Ecologie Evolutive' and 'Forme, Evolution et Diversité' of the Centre National de la Recherche Scientifique (CNRS) laboratory Biogéosciences. Finally, we thank G. A. Parker, M. Thiel, and an anonymous reviewer for their helpful comments on the manuscript.

\section{LITERATURE CITED}

Baeza JA, Stotz WB (2001) Host-use pattern and host-selection during ontogeny of the commensal crab Allopetrolisthes spinifrons ( $\mathrm{H}$. Milne Edwards, 1837) (Decapoda: Anomura: Porcellanidae). J Nat Hist 35:341-355

Baeza JA, Thiel M (2007) The mating system of symbiotic crustaceans: a conceptual model based on optimality and ecological constraints. In: Duffy JE, Thiel M (eds) Evolutionary ecology of social and sexual systems: crustaceans as model organisms. Oxford University Press, Oxford, p 249-267

> Baeza JA, Stotz WB, Thiel M (2002) Agonistic behaviour and development of territoriality during ontogeny of the sea anemone dwelling crab Allopetrolisthes spinifrons. Mar Freshw Behav Physiol 35:189-202

Bell JL, Stancyk SE (1983) Population dynamics and reproduction of Dissodactylus mellitae (Brachyura: Pinnotheridae) on its sand dollar host Mellita quinquiesperforata (Echinodermata). Mar Ecol Prog Ser 13:141-149

Brown SP, Renaud F, Guégan JF, Thomas F (2001) Evolution of trophic transmission in parasites: the need to reach a mating place? J Evol Biol 14:815-820

Chesher RH (1969) Contributions to the biology of Meoma ventricosa (Echinoidea: Spatangoida). Bull Mar Sci 19: 72-110

> Choisy M, Brown SP, Lafferty KD, Thomas F (2003) Evolution of trophic transmission in parasites: why add intermediate hosts? Am Nat 162:172-181

Combes C (2001) Parasitism: the ecology and evolution of intimate interactions. University of Chicago Press, Chicago, IL

De Bruyn C, Rigaud T, David B, De Ridder C (2009) Nature and consequences of the symbiotic relationship between the crab Dissodactylus primitivus and its echinoid host Meoma ventricosa. Mar Ecol Prog Ser 375:173-183

- Gandon S (2004) Evolution of multihost parasites. Evolution 58:455-469

George SB, Boone S (2003) The ectosymbiont crab Dissodactylus mellitae-sand dollar Mellita isometra relationship. J Exp Mar Biol Ecol 294:235-255

Gray IE, McCloskey LR, Weihe SC (1968) The commensal crab Dissodactylus mellitae and its reaction to sand dollar host factor. J Elisha Mitchell Sci Soc 84:472-481

Griffith H (1987a) Taxonomy of the genus Dissodactylus (Crustacea: Brachyura: Pinnotheridae) with descriptions of three new species. Bull Mar Sci 40:397-422

Griffith H (1987b) Phylogenetic relationships and evolution in the genus Dissodactylus Smith, 1870 (Crustacea: Brachyura: Pinnotheridae). Can J Zool 65:2292-2310

Guinot D (1979) Morphologie et phylogenèse des brachyoures. Mém Mus Hist Nat Sér A 112:171-250

Hammond LD (1982) Patterns of feeding and activity in deposit-feeding holothurians and echinoids (Echinodermata) from a shallow back-reef lagoon, Discovery Bay, Jamaica. Bull Mar Sci 32:549-571 
Johnson IS (1952) The demonstration of a 'host-factor' in commensal crabs. Trans Kans Acad Sci 55:458-464

Joshi A, Thompson JN (1995) Trade-offs and the evolution of host specialization. Evol Ecol 9:82-92

Kier PM, Grant RE (1965) Echinoid distribution and habits, Key Largo coral reef preserve, Florida. Smithson Misc Collect 149:1-68

Loot G, Park YS, Lek S, Brosse S (2006) Encounter rate between local populations shapes host selection in complex parasite life cycle. Biol J Linn Soc 89:99-106

Morand S, Robert F, Connors VA (1995) Complexity in parasite life cycles: population biology of cestodes in fish. J Anim Ecol 64:256-264

Parker GA, Chubb JC, Ball MA, Roberts GN (2003) Evolution of complex life cycles in helminth parasites. Nature 425:480-484

Pedersen AB, Altizer S, Poss M, Cunningham AA, Nunn CL (2005) Patterns of host specificity and transmission among parasites of wild primates. Int J Parasitol 35:647-657

Pohle G (1989) Development and morphology of laboratoryreared larvae of Dissodactylus nitidus (Smith 1840) (Decapoda: Brachyura), with a discussion of phylogenetic aspects in the Pinnotheridae. J Crustac Biol 9:278-296

Editorial responsibility: John Lawrence,

Tampa, Florida, USA
Pohle G, Marques F (1995) First zoea of Dissodactylus glasselli Rioja and new range and host records for species of Dissodactylus (Brachyura: Pinnotheridae), with a discussion of host-symbiont biogeography. Proc Biol Soc Wash 108:247-253

Poulin R (2007) Evolutionary ecology of parasites, 2nd edn. Princeton University Press, Princeton, NJ

Quinn GP, Keough MJ (2002) Experimental design and data analysis for biologists. Cambridge University Press, Cambridge

Rauch G, Kalbe M, Reusch TBH (2005) How a complex life cycle can improve a parasite's sex life. J Evol Biol 18:1069-1075

Reeves MN, Brooks WR (2001) Host selection, chemical detection, and protection of the symbiotic Pinnotherid crabs Dissodactylus crinitichelis and Clypeasterophilus rugatus associated with echinoderms. Symbiosis 30:239-256

Telford M (1978) Post-larval growth in two species of Dissodactylus (Brachyura: Pinnotheridae). Bull Mar Sci 28: 645-650

Telford M (1982) Echinoderm spine structure, feeding and host relationship of four species of Dissodactylus (Brachyura: Pinnotheridae). Bull Mar Sci 32:584-594

Submitted: June 16, 2009; Accepted: September 9, 2009

Proofs received from author(s): December 1, 2009 